This is the post print version of the article, which has been published in

Corporate Governance: The international journal of business in society. 2018, 18 (6),

1057-1073. https://doi.org/10.1108/CG-12-2017-0301

The Institutional Repository of University of Tampere

\title{
Foreign board members and firm innovativeness: An exploratory analysis for setting a research agenda
}

\author{
Teemu Makkonen ${ }^{1 ; 2 ; *}$, Allan M. Williams ${ }^{3}$ \& Antoine Habersetzer ${ }^{4}$ \\ ${ }^{1}$ Institute for Advanced Social Research, University of Tampere \\ Ratapihankatu 55, FI-33014 University of Tampere, Finland \\ Phone: +35850509 9133, email: teemu.makkonen@uta.fi \\ ${ }^{2}$ Department of Business and Economics, University of Southern Denmark \\ Alsion 2, DK-6400 Sфnderborg, Denmark \\ ${ }^{3}$ School of Hospitality and Tourism Management, University of Surrey \\ AP Building, Guildford, Surrey, GU2 7XH, UK \\ Phone: +44 148368 6308, email: allan.williams@surrey.ac.uk \\ ${ }^{4}$ Institute of Geography, University of Bern \\ Hallerstrasse 12, CH-3012 Bern, Switzerland \\ Phone: +41316315269,email: antoine.habersetzer@giub.unibe.ch \\ * Corresponding author
}

Purpose: This study seeks to assess the often repeated, but empirically unconfirmed, supposition that there is a positive connection between foreign board members (FBMs) and firm innovativeness, and to set a research agenda for future studies on the topic.

Design: The analyses are based on a large sample of firms within the European Union, utilizing patent and trademark data together with information on the national diversity of the boards.

Findings: The analyses confirm that there is a positive association between FBMs and firm innovativeness. Contrary to expectations, FBMs from less innovative countries than the countries of their host companies are more often associated with innovative firms than are FBMs from more innovative countries.

Research implications: This study provides empirical support for propositions, drawn from resource dependency theory and group effectiveness/diversity theories, that diverse boards of directors can lead to greater firm-level creativity and innovativeness. It also outlines a detailed research agenda for future studies to build on the tentative findings presented in this paper. 
Practical implications: The findings suggest that greater national diversity in the board of directors can enhance innovation.

Originality: Earlier studies on board diversity have not analysed empirically the issue of national diversity. The originality of this paper lies in its attempt to address this gap in the corporate governance literature.

Keywords: Board of Directors; Corporate Governance; Diversity; European Union; Foreign Board Members; Innovation

\section{INTRODUCTION}

Research on corporate governance has recently begun to investigate the links between board diversity, particularly in terms of gender diversity, and innovation (Torchia et al., 2011; Galia and Zenou, 2012; Adams et al., 2015). While most accounts hypothesize that national diversity (e.g. foreign workers) provide different perspectives that contribute to greater variety of ideas and enhanced innovation in the firm, these notions have mostly remained entirely theoretical (Solheim and Fitjar, 2016). This applies also in the case of board diversity and innovation: there is no systematic empirical evidence corroborating the supposition of a positive relationship between foreign board members (FBMs) and firm innovativeness ${ }^{[1]}$. Therefore, the originality of this paper lies in its attempt to address this gap between the theoretical debates and the lack of empirical accounts within the corporate governance literature. Specifically, the following two research questions are addressed: 1) are firms with FBMs more innovative and 2) are firms with FBMs from more innovative countries more innovative than those with FBMs from less innovative countries? To address these questions, the relationship between FBMs and the innovation activities of some 1545000 currently active firms in the European Union (EU) are explored, utilizing the Orbis database (Bureau van Dijk, 2016). 


\section{LITERATURE REVIEW AND HYPOTHESES}

A definite trend towards boards becoming more multinational has been observed, indicating that having FBMs and foreigners in other top management positions has become increasingly commonplace (Staples, 2007; Nielsen and Nielsen, 2010). Accordingly, in the 1980's Hambrick and Mason (1984) had already argued that firm-level innovations are strongly associated with the views, backgrounds and experiences of top management teams, i.e. the "upper echelons". In the contemporary globalized world, also FBMs may play an important role in the innovativeness of their host companies. While no direct evidence exists on the link between FBMs and firm-level innovativeness, some studies have investigated the potential impacts that FBMs could have on firm-level performance and corporate governance (e.g. Oxelheim and Randøy, 2005; Choi et al., 2012). This literature has commonly agreed that board diversity has a positive impact on firm reputation and performance, supporting the positive aspects of "national diversity" in board rooms.

With the positive relationship between firm performance and FBMs in mind, the question arises to what extent FBMs might be associated with firm innovativeness. Innovation is commonly understood as a social process which heavily relies on the recombination of existing knowledge to form new knowledge (Kogut and Zander, 2007). Consequently, a diverse board with board members (BMs) with different backgrounds supposedly grants more opportunities for novel knowledge combinations, and thus innovations. When framing the discussion on board diversity and firm-level innovativeness, two commonly identified reference points are: 1) resource dependency theory, and 2) group effectiveness/diversity theories. The resource dependency theory focuses on the availability of, and the possibilities for controlling, critical resources that are of utmost importance for the performance and survival of firms (Pfeffer and Salancik, 1978). Similarly, the group effectiveness/diversity theories assume that a diverse 
board of directors will lead to a wider set of perspectives, ideas, expertise and skill, which can result in greater creativity and innovativeness (Ruigrok et al., 2006; van Veen et al., 2014). Thus, a diversified board of directors with varying nationalities can be a valuable asset due to the variety of additional (knowledge) resources that the FBMs bring into the firm via their skills and expertise (Ruigrok et al., 2006; Eulerich et al., 2013). In the case of FBMs, this is particularly related to their additional international network contacts and knowledge sources (Arnegger et al., 2014). Notably, firms with FBMs can be expected to engage in a wider set of international relationships, which in turn are expected to lead to higher levels of innovation (cf. Solheim and Fitjar, 2016).

Based on these general theories, diverse boards, for example in terms of ethnicity and gender, have been empirically linked to stronger firm-level performance (Arena et al., 2015; Toumi et al., 2016) and innovativeness (Galia and Zenou, 2012; Zona et al., 2013; Cook and Glass, 2015). Of course, with increasing national board diversity there are potential time consuming conflicts and transaction costs associated with cultural and institutional (e.g. laws and regulations) distance, and the use of non-native languages in board meeting. However, the existing literature has frequently conceptually deduced that firms with FBMs are likely to be more innovative and creative than firms with solely national BMs (Eulerich et al., 2013; van Veen et al., 2014; Piekkari et al., 2015). Moreover, the assumption of a positive association between FBMs and firm-level innovativeness sits comfortably alongside most of the related literature on ethnic and gender diversity (Basset-Jones, 2005; Torchia et al., 2011; Nathan and Lee, 2013). While there are, of course, reasons for board membership other than those strictly related to innovation, the above notions lead to our first hypothesis. As discussed in the resource dependency and group effectiveness/diversity theories, diversified board of directors with varying nationalities are assumed to constitute a valuable asset for a firm, since they bring 
in a wider set of ideas and additional knowledge resources (Rice et al. 2012). Therefore, we assume that board diversity in terms of FBMs - as in the cases of ethnic and gender diversity - also has a positive association with firm-level innovativeness (based on patents and trademarks; see Section "Innovativeness" below):

Hypothesis 1. Firms with FBMs are more innovative than firms that do not have FBMs.

It is not only relevant to ask whether there are FBMs but also where these FBMs come from: less innovative countries are commonly considered to have fewer top-level managers living and working in foreign countries compared to highly innovative countries (cf. van Veen and Marsman, 2008). It could be argued that there might be little for the firm to learn from FBMs originating from countries that have laggard innovation performance. This is how the relationship is commonly perceived, for example, in the case of post-communist countries, which at one point were strongly dependent on Western countries for technological aid and assistance (Michailova and Jormanainen, 2011). As such, firms from advanced countries have invested in less developed ones to diversify their products to fit these growing markets (Gerybadze and Merk, 2014). Consequently, the literature on cross-border knowledge transfer has hypothesized that the magnitude of the knowledge transferred from international sources will tend to increase in relation to the quality gap between the origin and destination of these knowledge flows (Kotabe et al., 2007). Since, less-developed countries can benefit from connections to technologically and economically advanced countries (Levin and Barnard, 2013), it is reasonable to assume that FBMs from more innovative countries (based on the ranking of the country in the "Innovation Union Scoreboard"; see Section "Innovativeness" below) are likely to have a greater potential impact on the innovativeness of firms in less advanced countries than the other way around. In short, and in accordance with the resource 
dependency theory, the networks of FBMs from highly advanced countries can link the company to the (more) sophisticated knowledge and technology of their home countries. Therefore, the second hypothesis is that:

Hypothesis 2. Firms with FBMs from more innovative countries are more innovative than firms with FBMs from less innovative countries.

In order to realise innovation gains from cross-border knowledge transfers, the firms must have sufficient capacity to acquire, assimilate and exploit the transferred knowledge: this is termed as "absorptive capacity" (Cohen and Levinthal, 1990; Zahra and Gerard, 2002). There is considerable literature stressing that, without the necessary absorptive capacity, the recipient of advanced new knowledge will be constrained in terms of being able to benefit from it (Liu and Buck, 2007; Mancusi, 2008). It has also been emphasised that by facilitating access to, and absorption of, external knowledge, (foreign) BMs are important components of firms' absorptive capacity (Zahra et al., 2009; Giannetti et al., 2015). Firms with larger existing stocks of knowledge will also generally be more capable of absorbing new knowledge. Absorptive capacity is greatest when actors (in this case BMs) share similar technological backgrounds. In contrast, high technological distance would increase novelty value, but the absorptive capacity would be insufficient to make use of the divergent knowledge (Nooteboom et al., 2007). In other words, the technological backgrounds of the FBMs and the firm should be sufficiently similar for the firm to understand and take advantage of the knowledge brought by the FBM, but dissimilar enough for there to be something new to learn. Since, the absorptive capacity is commonly measured through $\mathrm{R} \& \mathrm{D}$ and educational variables relating to the workforce (Kostopoulos et al., 2011), that is, through proxy input indicators of innovation, we consider that the innovative performance of the host and home country (based on the ranking of the 
country in the "Innovation Union Scoreboard"; see Section "Innovativeness" below) of FBMs is indicative of the technological distance between them. This is in line with earlier studies which have discussed the group effectiveness/diversity theory: these earlier studies have addressed how a more diversified board of directors will lead to a broader set of ideas, skills and perspectives (van Veen et al., 2014), but that diversified boards (in this case: distance in terms of technological expertise) face higher transaction costs in terms of e.g. increased risk of conflict, communication problems and the longer times required for consensus building (Goodstein et al., 1994; van der Walt et al., 2006; Piekkari et al., 2015). Therefore, lastly we hypothesize that:

Hypothesis 3. Firms with FBMs from countries with relatively similar innovative capabilities are more innovative than firms with FBMs from countries with significantly lower or higher innovative capabilities.

These issues are also related to firm size: board diversity increases with firm size, but at decreasing rates (Arnegger et al., 2014). Moreover, there is considerable literature which discusses the relationship between size and the innovativeness of firms (Kleinknecht, 1989; Dolfsma and van der Velde, 2014). Therefore, since both themes which are studied here, that is board diversity and firm innovativeness, are strongly related to firm size (Zona et al., 2013), the analyses will be performed separately with aggregate level data and with data divided into different firm size classes. 


\section{DATA AND METHODS}

\section{Foreign board members}

In the case of FBMs, we use a dichotomous variable: one indicates that a company in a country has a FBM from another specific EU country, and zero indicates it has no FBMs. The sample properties in terms of the number of firms and shares of innovative firms are presented in Table

1. We decided to focus on the EU-28 countries, since the Union's internal freedom of movement and rights of residence mean that these countries have relatively similar institutional arrangements in respect of working or living abroad in the other Member States. Of course, even though EU legislation guarantees the free movement of workers within the EU, other issues - such as institutional and cultural differences - still impede board internationalization (van Veen and Elbertsen, 2008; Arnaboldi and Casu, 2011). However, the importance of FBMs has been acknowledged by the European Commission (2011), which is aiming to harmonize (some of) these differences. 
Table 1. Sample properties per country

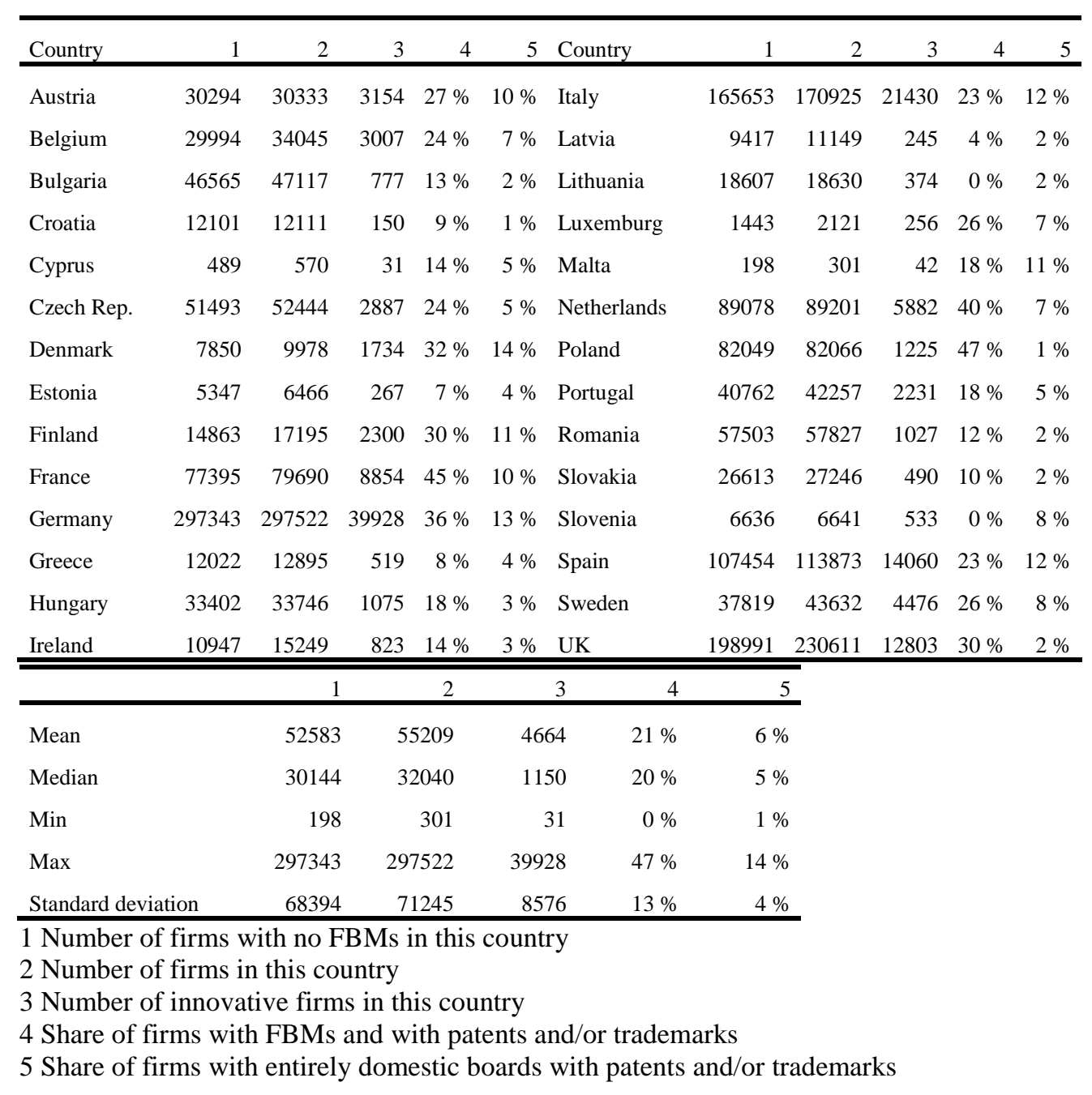

\section{Innovativeness}

Firm innovativeness: Patents and trademarks are used here to signal whether the firm is innovative. In line with Santamaría et al. (2009), we use a dichotomous variable: one if a company has been granted either a patent or a trademark and zero if not. For example, Acs et al. (2002) have shown empirically that patents act as a valid measure of innovative activity, providing in-depth information on technological product innovation, whereas for example Mendonca et al. (2004) have shown the validity of trademark analysis, which capture relevant aspects of innovation and the process of industrial change, when measuring service innovation. As such, the two indicators complement each other: patents as a measure of technological 
product innovation and trademarks as a measure of service innovation. Using these (dichotomous) approaches to firm innovativeness (innovative vs. non-innovative firms) based on secondary data can be criticized for failing to capture the complexity of innovation. However, the same logic is also widely used in studies using primary data collected through questionnaires or interviews, utilizing questions such as 'Has your company introduced an innovation? Yes/No'. The most notable example of this is the Community Innovation Survey of the European Union. Notwithstanding, this paper also acknowledges that relying only on patents and trademarks has limitations, mainly because they do not account for all types of innovation and since not all patents and trademarks lead to new products or services being introduced into the market.

Home and host country innovativeness of foreign board members: The "Innovation Union Scoreboard" was utilized to classify the EU-28 countries according to their innovation performance. Therefore, for $\mathrm{H} 2$ we observe the pair-wise links of FBMs from countries that are: a) more innovative and b) less innovative than the host country. For H3 we examine the pair-wise links of FBMs based on the reported innovation performance groups of their home countries (European Commission, 2015: p.5). Although composite metrics, such as the Innovation Union Scoreboard have been widely used in studies of innovation and internationalization (e.g. Filippetti et al., 2011), it is acknowledged that it is problematic to use these country-level data to analyse the potential innovativeness of individual FBMs. However, the index does provide coherent and up-to-date proxy data for national variations in the expected innovativeness of FBMs that otherwise would remain unaccounted for in the scale of analysis applied in this study. Similar approaches (i.e. using country-level determinants of FBM recruitment processes) have been used before as a logical first step to explore this rarely studied phenomenon (e.g. van Veen et al., 2014). 


\section{Data, sample and methods}

Data was derived data from the Orbis database (Bureau van Dijk, 2016) containing management, financial and ownership information on over 200 million private and listed companies worldwide. Pair-wise data was collected on the number of firms with foreign members of the board of directors according to their countries of nationality (as reported in the Orbis database) for both host and home country. Additionally, the number of firms that do not have FBMs was also recorded. All these search procedures were undertaken separately in the case of innovative and non-innovative firms for three different size classes, based on the standard Eurostat classification: small (10-49 employees), medium-sized (50-249 employees) and large ( $\geq 250$ employees) firms as well as for the aggregated total numbers. The following double dichotomy was utilized (see sample properties in Table 2 and a graphic overview in Figure 1):

1) Number of innovative firms per country divided into:

a. Firms that have FBMs in terms of the home country of these BMs (e.g. the number of Austrian firms with a patent and/or a trademark and at least one BM from another specific EU country)

b. Firms that do not have FBMs (e.g. the number of Austrian firms with a patent and/or a trademark with only Austrian BMs)

2) Number of non-innovative firms per country divided into:

a. Firms that have FBMs in terms of the home country of these BMs

b. Firms that do not have FBMs 
Table 2. The distribution of foreign board members and innovative firms across the size classes of the sample

\begin{tabular}{llll}
\hline Size group & Share of firms & Firms with/without & Innovative/non- \\
& & foreign BMs from EU-28 & innovative firms \\
\hline Small & $78 \%$ & $3 \% / 97 \%$ & $5 \% / 95 \%$ \\
Medium-Sized & $18 \%$ & $10 \% / 90 \%$ & $16 \% / 84 \%$ \\
Large & $4 \%$ & $20 \% / 80 \%$ & $31 \% / 69 \%$ \\
Total & $100 \%$ & $5 \% / 95 \%$ & $8 \% / 92 \%$ \\
\hline
\end{tabular}

1) Innovative firms

Firms with patent(s) and/or trademark(s)

1a) with FBMs 1b) with only domestic BMs
2) Non-innovative firms

2a) with FBMs 2b) with only domestic BMs

Figure 1. A graphic overview on sample categories.

The resulting sample includes an impressive number of 1545841 currently active firms within the EU 28: the data were collected between November 22nd and 23th 2016. Thus, the data on the BMs and firms with patents and/or trademarks corresponds to the situation at the end of 2016. Due to the EU-wide focus, and the resulting size of the sample, and as the Orbis database does not give access to time-series datasets, a cross sectional analysis is undertaken at this stage. The majority (circa 78\%) of the firms in the sample are small firms. When measured with patents and trademarks, circa $8 \%$ of the companies in the sample can be considered to be innovative (i.e. have been granted a patent or a trademark). The number of innovative firms per country is presented in Table 1 . There are, of course, wide variations in the share of innovative countries across the EU countries, while firm size is also important: the larger the size class of the firm, the more likely it is that a firm has a FBM (from another EU country) and that it owns a patent or a trademark and can, thus, be considered innovative (Table 2). 
While the database has some missing, incomplete and inconsistent information (i.e. there may be some errors in e.g. the reported nationalities of the BMs), the reliability of the Orbis database and measures it includes are widely considered to meet high standards: the database provides respectable coverage of European firms and has been evaluated to be generally reliable, credible and coherent (Pinto Ribeiro et al., 2010).

Mann Whitney U tests are used to assess the statistical differences between country groups to explore the innovative performance of firms with and without FBMs. The method of analysis used in this study is in line with several earlier studies of board diversity and firm performance (e.g. Virtanen, 2012; Joecks et al., 2013; Zainal et al., 2013), and based on the fact that the variable describing whether firms have or do not have FBMs is categorical. This has limitations concerning the endogeneity problem in terms of, for example, simultaneous causality. Therefore, more elaborate approaches will be needed to test the initial exploratory statements made in this paper. This will be discussed further in the concluding chapter.

Additionally, descriptive statistics, graphical illustrations and a decision tree are provided to underline key statements and to clarify the implications of the findings. The results, thus, provide a good overview of the associations between FBMs and firm-level innovativeness. However, it is noted that the tenure of a FBM and the term of a patent (the period it is in force) do not always coincide. Therefore, an important limitation is that, at this stage, associations rather than causality are examined. Since this paper provides an initial overview of the novel topic at hand, the data collection efforts required to analyse causality are beyond its scope: that would require more sophisticated time-series firm-matched data for the years when FBMs have been on the boards, as well as data on the years when patents and trademarks have been granted. However, due to the relatively large sample employed, the findings do provide a reliable picture 
of whether there is an association between FBMs and the innovativeness of the firm. This is the (very) first step towards investigating causal relationships: without the presence of such an association, it would be unlikely that there are causal relationships between the investigated variables.

\section{RESULTS}

Figure 2 presents an overview of the results in relation to $\mathrm{H} 1$, namely the percentages of innovative firms amongst those firms with FBMs from another EU-28 country compared to the baseline of innovative firms without FBMs. The graphical outline of the results already hints at a conclusion, namely that, irrespective of the institutional and legislative differences between EU Member States, firms throughout the EU with FBMs from other EU-28 countries are more innovative than firms without FBMs. In 26 out of the 28 EU-countries, the share of innovative firms is higher among firms with FBMs compared to the share of innovative firms among companies with solely domestic board rooms (Table 1$)$. Further, in $72 \%$ of cases $(\mathrm{N}=565$ pairwise country comparisons), the values are higher for firms with FBMs from a specific EU-28 country compared to the baseline of companies that do not have FBMs. If pair-wise comparisons with scores of $0 \%$ and $100 \%$ are excluded as outliers (since, they are in almost every case the outcome of a single or very few observations), the corresponding figure rises to 99\% ( $\mathrm{N}=394$ pair-wise country comparisons) (Figure 2). Bearing in mind that the majority of our sample is formed of non-innovative small firms without FBMs, including these in the analysis lowers the country-wise aggregate baseline of innovative companies that do not have FBMs. Therefore, the above reported aggregate figure is higher than the corresponding figures for small, medium-sized and large firms that are $96 \%, 90 \%$ and $89 \%$ respectively $(0 \%$ and $100 \%$ excluded). These results underline not only the connection between FBMs and firm-level innovativeness but also their connection to firm size: it is rare for small firms to have FBMs 
but, when they do, these companies are often innovative. Even though no claim is made of there being a causal relation, a strong association exists between FBMs and firm innovativeness. Thus, the results confirm the hypothesis (H1) that firms with FBMs are more innovative than firms that do not have FBMs.

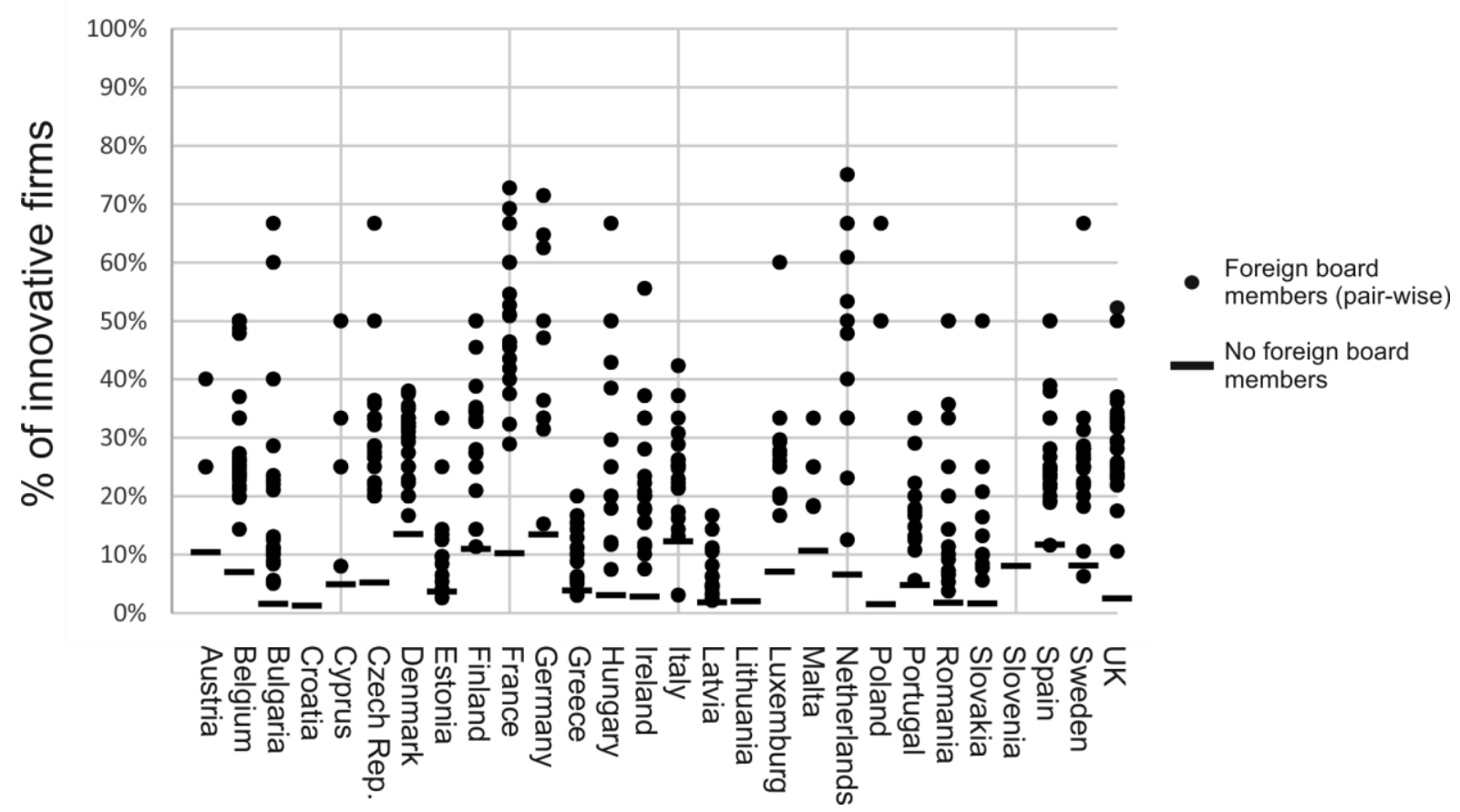

Figure 2. Overview of the connection between FBMs (within the EU-28) and firm-level innovativeness according to the pair-wise country comparisons (0\% and $100 \%$ excluded)

In the case of $\mathrm{H} 2$, the data show that there are more likely to be FBMs from more innovative than less innovative countries. This is the case in 19 out of the 26 (the most - Sweden - and the least - Romania - innovative countries have been excluded) countries included, after normalizing the figures according to the total number of firms in the home countries, i.e. by the size of the national economy of the foreign BMs. The countries showing contrasting evidence can be explained almost solely by reference to geographical proximity. For example, in the cases of 1) Cyprus, 2) Czech Republic, 3) Lithuania and 4) Portugal, the contrasting evidence is explained through the high numbers of foreign BMs from their immediate but less 
innovative neighbours: 1) Greece, 2) Slovakia, 3) Latvia and 4) Spain, respectively. This, of course, can also applies inversely, as high figures can be influenced by more innovative neighbours. Therefore, we sought to control for this geographical "bias" by repeating the comparison, after the "flows" of foreign BMs from "neighbouring countries", defined by border contiguity, had been excluded. As a result, out of the initially identified seven countries only two countries continued to show evidence that FBMs would come from less innovative countries underlining the "neighbourhood effect" in the origins of FBMs.

However, the direct opposite of what was predicted based on the literature is observed in one important respect: instead of firms with FBMs from more innovative countries being more innovative, it is the other way around. According to the pair-wise country comparisons, firms with FBMs from less innovative countries are more innovative (Figure 3a). A Mann Whitney $\mathrm{U}$ test indicates that, when all comparisons are included, this difference is statistically significant at a level of $p<0.001(\mathrm{~N}=290$ and 274 for country-wise comparisons with FBMs from more and less innovative countries respectively). These results $(p<0.001)$ hold for all size classes: small, medium-sized and large firms. The significance remains at a level of $p<0.001$ even when pair-wise comparisons with scores of $0 \%$ and $100 \%$ were excluded as above $(\mathrm{N}=201$ and 193 for country-wise comparisons with FBMs from more and less innovative counties respectively). As stated, this contrasts with our hypothesis (H2) and expectations based on the existing literature.

With regards to $\mathrm{H} 3$, we divided the pair-wise country comparisons into different groups depending on the origin of the FBMs i.e. whether they are from more or less innovative countries. Specifically in accordance with the Innovation Union Scoreboard (European Commission, 2015: p.5), pair-wise comparisons were defined where the FBMs are coming: 1) 
from a country belonging to a significantly higher innovation performance group as "Higher +2 " (e.g. Swedish BMs in Estonia), 2) from a country that is in a slightly higher innovation performance group as "Higher" (e.g. Irish BMs in Italy), 3) from within the same performance group as "Same" (e.g. Finnish BMs in Germany) and analogously vice versa 4) "Lower" and 5) "Lower -2". From Figure $3 \mathrm{~b}$ we can observe that when the innovation performance group of the FBMs' home countries is lower compared to the host country of their firms, the firms in question are more often innovative rather than the other way around. The Mann Whitney U tests confirm most of these differences to be statistically significant when all comparisons are included in the analysis, and when scores of $0 \%$ and $100 \%$ were excluded (Table 3). The analyses were repeated for the different size classes and the results largely follow the aggregate picture presented above. However, whereas in the case of small firms the statistically significant results were much in line with the aggregate results, the corresponding figures for medium-sized and large companies displayed less statistically significant differences between the innovation performance groups of the host and home countries of $\mathrm{FBMs}^{[2]}$. Thus, here again, firm size is relevant to the connection between FBMs and firm-level innovativeness.

Table 3. Reported p-values for Mann Whitney U tests between differences in the innovation performance groups

\begin{tabular}{|c|c|c|c|c|c|c|c|c|}
\hline \multirow[b]{3}{*}{ Higher } & \multicolumn{2}{|c|}{ Higher +2 } & \multicolumn{2}{|c|}{ Higher } & \multirow{2}{*}{\multicolumn{2}{|c|}{ Same }} & \multirow{2}{*}{\multicolumn{2}{|c|}{ Lower }} \\
\hline & \multicolumn{4}{|c|}{ All included $/ 0 \%$ and $100 \%$ excluded } & & & & \\
\hline & 0.157 & $/ 0.014 *$ & & & & & & \\
\hline Same & $0.049 *$ & $\mid<0.001 * * *$ & 0.307 & $/ 0.003 * *$ & & & & \\
\hline Lower & \multicolumn{2}{|c|}{$<0.001 * * * /<0.001 * * *$} & \multicolumn{2}{|c|}{$<0.001 * * * /<0.001 * * *$} & $0.002 * *$ & $/ \mathbf{0 . 0 3 7} *$ & & \\
\hline Lower -2 & $0.035 *$ & $\mid<0.001 * * *$ & 0.222 & $/ 0.040 *$ & 0.785 & $/ 0.642$ & $0.020 *$ & $/ 0.029 *$ \\
\hline
\end{tabular}

Notes: Significant at the level of $*<0.05 ; * *<0.01 ; * * *<0.001$. Number of comparisons: Higher $+2=75 / 56$; Higher=144/101; Same=160/101; Lower=120/93; Lower $-2=65 / 43$ 

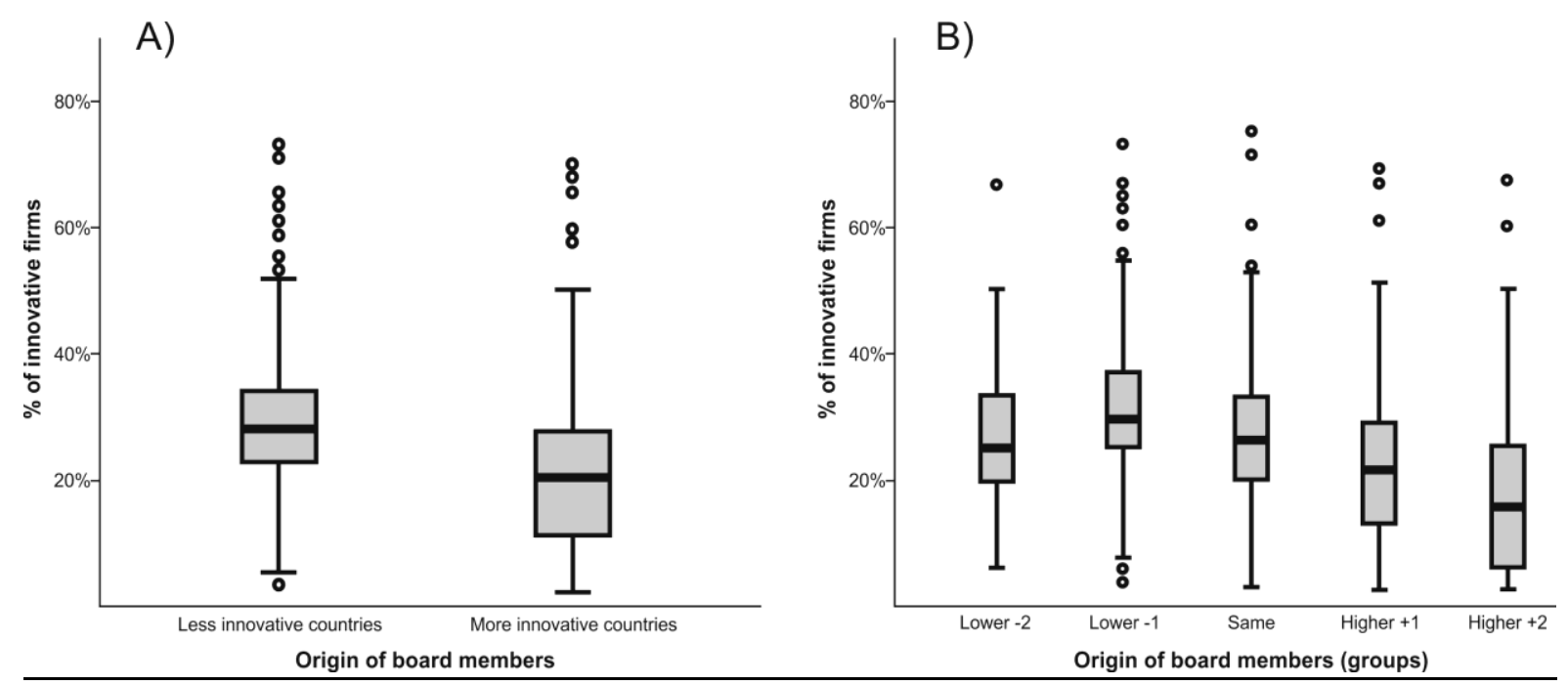

Figure 3. The shares of innovative firms with FBMs (within the EU-28) from (A) more and less innovative countries and $(B)$ higher or lower innovation performance groups according to the pairwise country comparisons (0\% and $100 \%$ excluded)

These results do not support our hypothesis (H3), based on the existing literature, which suggested that large differences between the levels of innovativeness of host and home countries would negatively affect the impact of FBMs on the innovativeness of firms in a similar fashion at both ends of the spectrum. Thus, we expected the relationship to be concave with the "Similar" group having the highest shares of innovative firms. However, as can be observed from the group "Lower -2 " (Figure 3b), there seems to be a threshold in the gap between the low innovativeness of the home and high innovativeness of the host countries of FBMs, after which the association with innovative firms is weaker. In other words, the relationship becomes concave once the difference between the home and host countries of BMs is sufficiently large.

In addition, if we consider our overarching research concern in terms of the decision as to whether or not a company should have FBM, the results can be expressed in the form of a classification (or a decision) tree (cf. Schiehll and Bellavance, 2009; Sohn and Kim, 2012). As 
shown in Figure 4, the results of the classification tree support the findings of the earlier analysis: firms with FBMs are more innovative than firms that do not have FBMs, and firms with FBMs from less innovative countries (particularly if the difference is not too large as discussed above) are more likely to be innovative than firms with FBMs from more innovative countries as shown by the higher mean values. The modest $R^{2}$ value $(0.19)$, however, indicates that, naturally, board diversity is only one out of the several factors (including e.g. R\&D inputs) influencing the innovativeness of firms.

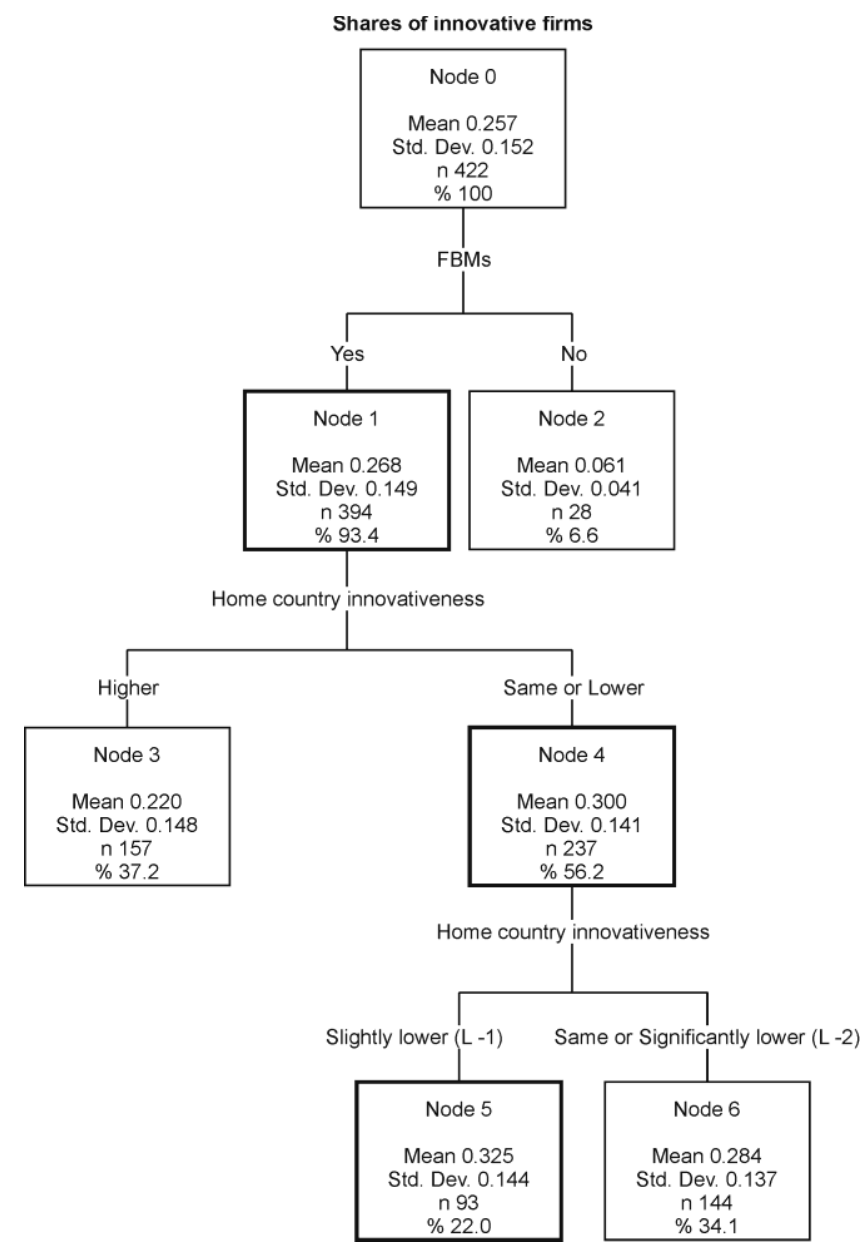

Figure 4. Classification tree depicting the share of innovative firms, as means, based on the "choice" of having or not having FBMs according to the pair-wise country comparisons (0\% and 100\% excluded) 


\section{DISCUSSION}

The hypothesis (H1) that there is a definite positive association between FBMs and innovative firms was confirmed. Moreover, firm level innovativeness seems to be more strongly related to the presence of FBMs in the case of small rather than medium-sized or large companies. This seems reasonable as medium-sized and large companies have more in-house capacities for innovation. In this logic, the additional knowledge of FBMs supposedly has a stronger impact in small companies, where in-house capabilities are more restricted than in mediumsized or large firms. However, the testing of the latter two hypotheses (H2 and H3) provided the unexpected finding that firms with FBMs from less innovative countries are more innovative than those with FBMs from more innovative countries; this contradicts the expectations, based on the literature review. Four potential (interlinked) explanations can be suggested to explain this finding.

Firstly, FBMs from less innovative countries might be positively associated with the innovativeness of firms in more innovative countries, because firms in more innovative countries might have a higher absorptive capacity. In contrast, firms from less innovative countries might lack sufficient absorptive capacity to make use of the knowledge possessed by BMs from more innovative countries ${ }^{[3]}$. That is, the "high tech economies" gain from "low tech country" BMs, due to their (potentially) higher absorptive capacities, but the inverse applies less frequently. As Nooteboom et al. (2007: p.1028) argue, "the more one already knows, the further afield one has to go, in more exotic directions, to still find something new". For companies in innovative countries this provides, on the one hand, an incentive to look for highly different types of knowledge, and on the other hand the capacity to make use of it. Contrarily, no matter how valuable the knowledge of their FBMs might be for acquiring new information and fostering innovation, without sufficient absorptive capacity firms in less 
technologically advanced countries may find it difficult to exploit the knowledge gained from FBMs from more innovative countries.

Secondly, the value of knowledge originating from less innovative countries may not be recognized. The issue relates to the value attached to the prestige of BMs from different settings. For example, Gupta and Govindarajan (2000) and Kumar (2013) have argued that due to a sense of superiority or a form of ethnocentrism - the perceived value of knowledge may be regarded as being much lower than it actually is if it originates from a less innovative country. Thus, there may be greater social recognition by other BMs of the value of the knowledge of BMs from highly innovative countries, and the latter are more likely to be considered as sources of innovation. Hence, it is possible that only the most exceptional individuals (the crème-de-la-crème) from less innovative countries are recruited as FBMs. They would then be expected to make an above average contribution to the innovation performance of these firms compared to BMs from more innovative countries.

Thirdly, and complementary to the second argument, FBMs from more innovative countries can be selected for motives other than for the competences they bring into the company (van der Walt and Ingley, 2003). For instance, FBMs from more innovative countries might be appointed to raise the visibility and prestige of the firm so as to make it more attractive for investors (Oxelheim and Randøy, 2005). Another possibility is that FBMs from more innovative countries might be appointed for reasons of ownership and control rather than innovation - including expansion, particularly through foreign direct investments, acquisition and mergers (Mizruchi, 1996; Choi et al., 2012). 
Lastly, the size of the boards is likely to be a factor facilitating the reported effects of FBMs vis-à-vis the innovativeness of the firm. It is logical to think that the larger the board the more likely it is to have FBMs from less innovative countries. Similarly, as shown by earlier empirical accounts (De Cleyn and Braet, 2012), the multitude of perspectives inherent in larger boards seem to enhance firms' innovativeness. Thus, larger boards are more likely than smaller ones to possess innovative ideas and are also more likely to include FBMs from less innovative countries. However, it has to be noted that due to increased coordination and communication costs, it might be more difficult for FBMs to get their voices heard in larger boards (Brunninge et al., 2012).

\section{CONCLUSIONS}

\section{Contributions and implications}

This paper has set out to explore the novel topic of FBMs and their association with the innovativeness of the firm, utilizing data collected from the Orbis database (Bureau van Dijk, 2016). In relation to our hypotheses and the existing literature, the following findings are especially notable. Firstly, firms with FBMs are more innovative than firms that do not have FBMs. This finding is in line with earlier studies (e.g. Cook and Glass, 2015) addressing the link between innovativeness and other types of board diversity (e.g. ethnicity and gender). An apparently more surprising finding was that our results did not corroborate the suggestion made in earlier studies that firms with FBMs from more innovative countries are more innovative. Instead, this paper found evidence for an inverse association: generally, firms with FBMs from less innovative countries are more likely to be innovative than firms with FBMs from more innovative countries. 
There are a number of potential interlinked explanations for this unexpected finding. Firms in more innovative countries are well equipped to utilize new ideas, whereas firms in lessdeveloped countries might lack the capacity to do the same (i.e. absorptive capacity or the lack thereof). Further, FBMs from less innovative countries are more critically evaluated and thus, on average, have to have stronger competences compared to FBMs from more innovative countries in order to be recruited as directors. Relatedly, FBMs from more innovative countries might be selected for reasons of prestige or ownership and control, and to a lesser extent for their competences with regard to innovation. Finally, board size can affect the results presented here, since larger boards are more likely to include FBMs from less innovative countries, and since it is likely that board size itself affects the innovativeness of the firm. In terms of a more general theoretical interpretation, our results support particularly perspectives of resource dependency theory and group effectiveness/diversity theories.

Given the exploratory nature of this paper, caution is required when formulating practical recommendations. Generally speaking, the existing literature is quite sparse in terms of expressing advice relating to the presence of FBMs in corporate boards. Most commonly, companies are advised to include FBMs in order to source additional knowledge (Ujunwa et $a l ., 2012$ ) or to increase the international credibility of the company (Oxelheim and Randøy, 2005). However, FBMs have not been recommended so far in relation to their innovative capabilities. Our results suggest that companies should pay more attention to the contribution of FBMs to the firm's innovativeness, and especially to the value of recruiting FBMs from less innovative countries. As outlined previously, it is often presumed that the flow of knowledge is directed from more innovative to less innovative countries (Michailova and Jormanainen, 2011). From this perspective, the positive association between the presence of FBMs from less innovative countries and the innovativeness of a company is somehow counterintuitive. This 
indicates the need to address this widespread intuition and, instead, to understand that FBMs from less innovative countries are potentially beneficial for a firm's innovative capability. Thus, instead of focusing on the practical implications, the results from this study encourage further research in this promising field: the origin of BMs is only one of many aspects that have to be taken into account when appointing new BMs, but our results do suggest that this merits closer examination, both in academic research and in strategic management practice. However, more inferential analysis, an agenda that is discussed in greater detail below, is needed to formulate more precise policy recommendations.

\section{Limitations and an agenda for future research}

It has to be noted that, due to its exploratory approach, the paper has a number of limitations, which suggest several directions for more detailed analyses which, thus, form a research agenda for future studies on the topic. Firstly, this agenda includes testing the impact of FBMs in different business sectors, as knowledge requirements are likely to be sectorally varied, as is the importance of innovation. Secondly, the role of cultural (e.g. in terms of language) and institutional (e.g. in terms of legislation) similarity, as well as board size, as moderating or facilitating factors of cross-border knowledge transfer driven by FBMs need to be evaluated with regression models (consistent with earlier literature). Adding variables such as the turnover, profitability and business segments of the firms, as well as the age, expertise and experience of the FBMs into the analysis will alleviate the risk of endogeneity present in descriptive approaches such as that utilized in this paper. This will require extensive procedures to collect the data for every firm in the sample, and, therefore, will most probably necessitate scholars to concentrate on smaller regional scales, such as individual countries, rather than the EU scale applied here. 
Thirdly, the analysis only covers certain aspects of innovation: technological product (measured by patents) and service (measured by trademarks) innovation. Thus, while patents and trademarks are valid proxy indicators for certain types of innovation (e.g. Acs et al., 2002; Mendonca et al., 2004), other types of innovation, such as organizational and marketing innovation, are not covered by these two measures. This is a limitation since, for example, the internationalization of markets and, thus, marketing innovations are likely to be factors that inform decisions to appoint FBMs, while it is reasonable to assume that FBMs should also have an impact on the level of organizational innovation within a firm. This shortcoming calls for applying the procedures and definitions presented for example in the Oslo Manual for collecting innovation data (OECD, 2005), accompanied by a specific set of questionnaire items to unravel the impacts of FBMs on innovation other than strict product (goods and services) innovation. That is, with survey data one would have a strong potential to analyse more closely the interaction between FBMs and different types of innovation. Moreover, our decision to use a (simple, non-discriminating) dichotomous variables ( 0 if no trademark or patent/if no FBMs and 1 if a patent and/or a trademark/FBMs), with no recognition of the number and quality of patents, trademarks and FBMs (i.e. no scale) is a limitation that constrains us from conducting more elaborate analyses, besides the chosen approach. Further analysis should also take into account this "scale" issue by exploring: 1) whether firms with FBMs are only marginally or significantly more innovative (have multiple patents and trademarks) than firms with solely domestic board rooms and 2) whether there are minimum or maximum thresholds, as suggested by the token theory (see Torchia et al., 2011), to the number of FBMs for them to have a significant influence on innovation.

Fourthly, the causal relationship between absorptive capacity, FBMs and firm innovativeness need to be more intensively explored. Our results give a first indication that the absorptive 
capacity of firms might limit knowledge transfer from FBMs. Future research could address this topic more specifically with more detailed datasets or primary data collected, for example, through surveys and more sophisticated methods (than the ones applied here) to quantify technological differences and the absorptive capacities of firms and BMs, and to establish causalities.

Fifthly, an obvious conclusion is that there is a need to acknowledge that FBMs can be selected for reasons other than to boost innovativeness. This generates a number of interesting questions, which include, for example, the following: To what extent are FBMs selected to boost the innovativeness of firms as opposed to being selected for other reasons, so that heightened innovativeness represents a form of additional or 'collateral' advantage? And are only the highly innovative crème-de-la-crème selected as FBMs from technologically less developed countries and, if so, how are they identified and recruited? These types of research questions will require an integrative and qualitative approach including interview data and firm annual reports.

Finally, we have purposefully avoided making a definite statement on the causal relationship between FBMs and firm innovativeness, since theoretically it is possible to argue for the existence of causality in both directions. It can be argued that FBMs increase a firm's innovativeness, and alternatively that innovative firms appoint more FBMs. Sophisticated time-series firm-matched data on the years that FBMs have joined the boards, as well as data on the years when patents and trademarks have been granted, are needed to tackle this shortcoming. However, and again, this will potentially reduce the sample sizes of studies on causality due to the amount of work needed to collect this kind of data. Since this paper provides more of an overview of the novel topic at hand utilizing reliable data (as shown e.g. 
by Pinto Ribeiro et al., 2010) from the Orbis database (Bureau van Dijk, 2016) for 28 EUcountries and roughly 1.5 million companies, the data collection efforts required to analyse causality are beyond its scope. Rather than providing a definitive answer to this question, the paper sought to assess whether an association between innovativeness and FBMs reveals a fruitful research area for further investigation to 1) suggest that the topic merits closer examination both in academic research and in corporate governance practice and 2) to contribute to the shaping of what remains a rather novel topic. The results and the proposed research agenda support this aim in general.

\section{NOTES}

${ }^{[1]}$ This is further elaborated by a thorough search procedure on board diversity and innovation utilizing the Scopus database by Elsevier: there were a handful of articles that presented empirical findings on the relationship between board diversity (in terms of ethnicity, gender, etc.) and the innovativeness of the firm, but none of them addressed the issue of FBMs underlining the empirical novelty of the topic.

${ }^{[2]}$ Results table can be obtained from the corresponding author upon request.

${ }^{[3]}$ These speculations are analogous to the discussion on absorptive capacity and technology transfer in EU's lagging regions and countries (cf. Oughton et al., 2002).

\section{REFERENCES}

Acs, Z., Anselin, L. and Varga, A. (2002), "Patents and innovation counts as measures of regional production of new knowledge", Research Policy, Vol. 31 No. 2, pp.1069-1085.

Adams, R., de Haan, J., Terjesen, S. and van Ees, H. (2015), "Board diversity: moving the field forward", Corporate Governance: International Review, Vol. 23 No. 2, pp.77-82.

Arena, C., Cirillo, A., Mussolino, D., Pulcinelli, I., Saggese, S. and Sarto F. (2015), "Women on board: evidence from a masculine industry", Corporate Governance, Vol. 15 No. 3, pp.339-356. 
Arnaboldi, F. and Casu, B. (2011), “Corporate governance in European banking”, in Barth, J., Lin, C. and Wihlborg, C. (Eds.), Research Handbook on International Banking and Governance, Edward Elgar, Cheltenham, pp.588-609.

Arnegger, M., Hofmann, C., Pull, K. and Vetter, K. (2014), "Firm size and board diversity", Journal of Management and Governance, Vol. 18 No. 4, pp.1109-1135.

Basset-Jones, N. (2005), "The paradox of diversity management, creativity and innovation", Creativity and Innovation Management, Vol. 14 No. 2, pp.169-175.

Brunninge, O., Nordqvist, M. and Wiklund, J. (2007), "Corporate governance and strategic change in SMEs", Small Business Economics, Vol. 29 No. 3, pp.295-308.

Bureau van Dijk (2016), “Orbis Database”, Accessed on November 23, 2016, from: https://orbis.bvdinfo.com/

Choi, H., Sul, W. and Min, S. (2012), "Foreign board membership and firm value in Korea", Management Decision, Vol. 50 No. 2, pp.207-233.

Cohen, W. and Levinthal, D. (1990), “Absorptive capacity: a new perspective on learning and innovation”, Administrative Science Quarterly, Vol. 35 No. 1, pp.128-152.

Cook, A. and Glass, C. (2015), "Do minority leaders affect corporate practice? Analyzing the effect of leadership composition on governance and product development”, Strategic Organization, Vol. 13 No. 2, pp.117-140.

De Cleyn, S. and Braet, J. (2012), "Do board composition and investor type influence innovativeness in SMEs?”, International Entrepreneurship and Management Journal, Vol. 8 No. 3, pp.285-308.

Dolfsma, W. and van der Velde, G. (2014), “Industry innovativeness, firm size, and entrepreneurship", Journal of Evolutionary Economics, Vol. 24 No. 4, pp.713-736.

Eulerich, M., Velte, P. and van Uum, C. (2013), "The impact of management board diversity on corporate performance", Problems and Perspectives in Management, Vol. 11 No. 4, pp.23-37.

European Commission (2011), The EU Corporate Governance Framework, European Commission, Brussels. European Commission (2015), Innovation Union Scoreboard 2015, European Commission, Brussels.

Filippetti, A., Frenz, M. and Ietto-Gillies, G. (2011), “Are innovation and internationalization related?”, Industry and Innovation, Vol. 18 No. 5, pp.437-459.

Galia, F., and Zenou, E. (2012), “Board composition and forms of innovation”, European Journal of International Management, Vol. 6 No. 6, pp.630-650. 
Gerybadze, A. and Merk, S. (2014), "Globalisation of R\&D and host-country patenting of multinational corporations in emerging countries", International Journal of Technology Management, Vol. 64 Nos. 2-4, pp.148-179.

Giannetti, M., Liao, G. and Yu, X. (2015), “The brain gain of corporate boards”, Journal of Finance, Vol. 70 No. 4, pp.1629-1682.

Goodstein, J., Gautam, K. and Boeker, W. (1994), “The effects of board size and diversity on strategic change”, Strategic Management Journal, Vol. 15 No. 3, pp.241-250.

Gupta, A., and Govindarajan, V. (2000), "Knowledge flows within multinational corporations", Strategic Management Journal, Vol. 21 No. 4, pp.473-496.

Hambrick, D. and Mason, P. (1984), "Upper echelons: The organization as a reflection of its top managers", Academy of Management Review, Vol 9 No. 2, pp.193-206.

Joecks, J., Pull, K. and Vetter, K. (2013), “Gender diversity in the boardroom and firm performance”, Journal of Business Ethics, Vol. 118 No. 1, pp.61-72.

Kleinknecht, A. (1989), "Firm size and innovation”, Small Business Economics, Vol. 1 No. 3, pp.215-222.

Kogut, B. and Zander, U. (2007), "Knowledge of the firm, combinative capabilities, and the replication of technology”, Organization Science, Vol. 3 No. 3, pp.383-397.

Kostopoulos, K., Papalexandris, A., Papachroni, M. and Ioannou, G. (2011), “Absorptive capacity, innovation, and financial performance", Journal of Business Research, Vol. 64 No. 12, pp.1335-1343.

Kotabe, M., Dunlap-Hinkler, D., Parente, R. and Mishra, H. (2007), “Determinants of cross-national knowledge transfer and its effect on firm innovation", Journal of International Business Studies, Vol. 38 No. 2, pp.259282.

Kumar, N. (2013), "Managing reverse knowledge flow in multinational corporations", Journal of Knowledge Management, Vol. 17 No. 5, pp.695-708.

Levin, D. and Barnard, H. (2013), “Connections to distant knowledge: interpersonal ties between more- and lessdeveloped countries”, Journal of International Business Studies, Vol. 44 No. 7, pp.676-698.

Liu, X. and Buck, T. (2007), "Innovation performance and channels for international technology spillovers", Research Policy, Vol. 36 No. 3, pp.355-366.

Mancusi, M. (2008), "International spillovers and absorptive capacitys", Journal of International Economics, Vol. 76 No. 2, pp.155-165. 
Mendonca, S., Pereira, T. and Godinho, M. (2004), "Trademarks as an indicator of innovation and industrial change”, Research Policy, Vol. 33 No. 9, pp.1385-1404.

Michailova, S. and Jormanainen, I. (2011), “Knowledge transfer between Russian and Western firms”, Critical Perspectives on International Business, Vol. 7 No. 3, pp.250-270.

Mizruchi, M. (1996), "What do interlocks do? An analysis, critique, and assessment of research on interlocking directorates", Annual Review of Sociology, Vol. 22 No. 1, pp.271-298.

Nathan, M. and Lee, N. (2013), "Cultural diversity, innovation, and entrepreneurship", Economic Geography, Vol. 89 No. 4, pp.367-394.

Nielsen, S. and Nielsen, B. (2010), "Why do firms employ foreigners on their top management team?", International Journal of Cross Cultural Management, Vol. 10 No. 2, pp.195-209.

Nooteboom, B., van Haverbeke, W., Duysters, G., Gilsing, V. and van den Oord, A. (2007), "Optimal cognitive distance and absorptive capacity”, Research Policy, Vol. 36 No. 7, pp.1016-1034.

OECD (2005), Oslo Manual: Guidelines for Collecting and Interpreting Innovation Data, OECD Publishing, Paris.

Oxelheim, L. and Randøy, T. (2005), "The impact of foreign board membership on firm value", Journal of Banking and Finance, Vol. 27 No. 12, pp.2369-2392.

Oughton, C., Landabaso, M. and Morgan, K. (2002), "The regional innovation paradox: Innovation policy and industrial policy”, Journal of Technology Transfer, Vol. 27, No.1, pp.97-110.

Pfeffer, J. and Salancik, G. (1978), The External Control of Organizations: A Resource-Dependence Perspective, Harper and Rows, New York.

Piekkari, R., Oxelheim, L. and Randøy, T. (2015), “The silent board: how language diversity may influence the work processes of corporate boards", Corporate Governance: International Review, Vol. 23 No. 1, pp.25-41.

Pinto Ribeiro, S., Menghinello, S. and De Backer, K. (2010), “The OECD Orbis database: responding to the need for firm-level micro-data in the OECD”, OECD Statistics Working Papers, Vol. 2010 No. 1.

Rice, M., Tierney, S., O’Hagan, S., Lyons, D. \& Green, M. (2012), “Knowledge, influence, and firm-level change: A geographic analysis of board membership associated with Canada's growing and declining business", Geoforum, Vol. 43 No. 5, pp.959-968.

Ruigrok, W., Peck, S., Tacheva, S., Greve, P. and Hu, Y. (2006), "The determinants and effects of board nomination committees", Journal of Management and Governance, Vol. 10 No. 2, pp.119-148. 
Santamaría, L., Nieto, M. and Barge-Gil, A. (2009), "Beyond formal R\&D: taking advantage of other sources of innovation in low-and medium-technology industries”, Research Policy, Vol. 38 No. 3, pp.507-517.

Schiehll, E. and Bellavance, F. (2009), "Boards of directors, CEO ownership, and the use of non-financial performance measures in the CEO bonus plan", Corporate Governance: An International Review, Vol. 17 No. 1, pp.90-106.

Sohn, S. and Kim, J. (2012). "Decision tree-based technology credit scoring for start-up firms", Expert Systems with Applications, Vol. 39 No. 4, pp.4007-4012.

Solheim, M. and Fitjar, R. (2016), "Foreign workers are associated with innovation, but why?", International Regional Science Review, OnlineFirst, doi:10.1177/0160017615626217.

Staples, C. (2007), "Board globalisation in the world's largest TNCs 1993-2005", Corporate Governance: International Review, Vol. 15 No. 2, pp.311-321.

Torchia, M., Calabrò, A. and Huse, M. (2011), "Women directors on corporate boards", Journal of Business Ethics, Vol. 102 No. 2, pp.299-317.

Toumi, N., Benkraiem, R. and Hamrouni, A. (2016), "Board director disciplinary and cognitive influence on corporate value creation", Corporate Governance, Vol. 16 No. 3, pp.564-578

Ujunwa, A., Okoyeuzu, C. and Nwakoby, I. (2012), “Corporate board diversity and firm performance”, Review of International Comparative Management, Vol. 13 No. 4, pp.605-620.

van der Walt, N. and Ingley, C. (2003), "Board dynamics and the influence of professional background, gender and ethnic diversity of directors", Corporate Governance: International Review, Vol. 11 No. 3, pp.218-234. van der Walt, N., Ingley, C., Shergill, G. and Townsend, A. (2006), "Board configuration: Are diverse boards better boards?", Corporate Governance, Vol. 6 No. 2, pp.129-147.

van Veen, K. and Elbertsen, J. (2008), "Governance regimes and nationality diversity in corporate boards", Corporate Governance: International Review, Vol. 16 No. 5, pp.386-399.

van Veen, K. and Marsman, I. (2008), “How international are executive boards of European MNCs?”, European Management Journal, Vol. 26 No. 3, pp.188-198.

van Veen, K., Sahib, P. and Aangeenbrug, E. (2014), “Where do international board members come from?”, International Business Review, Vol. 23 No. 2, pp.407-417.

Virtanen, A. (2012), "Women on the boards of listed companies: Evidence from Finland", Journal of Management and Governance, Vol. 16 No. 4, pp.571-593. 
Zahra, S. and Gerard, G. (2002), “Absorptive capacity: a review, reconceptualization, and extension”, Academy of Management Review, Vol. 27 No. 2, pp.185-203.

Zahra, S., Filatotchev, I. and Wright, M. (2009), "How do threshold firms sustain corporate entrepreneurship?", Journal of Business Venturing, Vol. 24 No. 3, pp.248-260.

Zainal, D., Zulkifli, N. and Saleh, Z. (2013), "Corporate board diversity in Malaysia: A longitudinal analysis of gender and nationality diversity", International Journal of Academic Research in Accounting, Finance and Management Sciences, Vol. 3 No. 1, pp.136-148.

Zona, F., Zattoni, A. and Minichilli, A. (2013), “A contingency model of boards of directors and firm innovation”, British Journal of Management, Vol. 24 No. 3, pp.299-315. 